\title{
The impact of obesity on foot morphology in women aged 48 years or older
}

\author{
Kristína Tománková*, Miroslava Přidalová, and Aleš Gába \\ Faculty of Physical Culture, Palacký University Olomouc, Olomouc, Czech Republic
}

Copyright: (C) 2015 K. Tománková et al. This is an open access article licensed under the Creative Commons Attribution License (http://creativecommons.org/licenses/by/4.0/).

\begin{abstract}
Background: Obesity is major risk factor for many diseases within society and represents extensive loads for the feet which lead to various foot disorders and deformities. Objective: The aim of this study was to evaluate the impact of obesity as represented by percent body fat (PBF) on foot morphology. Methods: The study sample included 139 Czech women aged 48-69 years. The women were divided into two groups by PBF: non-obese women (NOW) $(n=66 ; \mathrm{PBF}<35 \%)$ and obese women (OW) $(n=73 ; \mathrm{PBF}>35 \%)$. Measurements included \% PBF and width, length and angle dimensions of foot. The Chippaux-Smirak index (CSI) was calculated for each foot. Results: We found significant differences between OW and NOW in these parameters: direct forefoot width $\left(\sin . p=.02, r_{\mathrm{pb}}=.20\right)$, direct heel width (sin. $p=.01, r_{\mathrm{pb}}=.22$; dex. $\left.p<.01, r_{\mathrm{pb}}=.22\right)$, hallux angle ( $\left.\sin . p=.01, r_{\mathrm{pb}}=.25\right)$ and CSI (sin. $p<.01$, $r_{\mathrm{pb}}=.26$; dex. $p<.01, r_{\mathrm{pb}}=.27$ ). The results showed that the mean values of the heel width and CSI were significantly higher in OW on both feet, the mean values of forefoot width only on the left foot. Conclusions: Results proved that obesity impacts all parts of the foot (heel, longitudinal foot arch, forefoot). Despite significant differences of the CSI between NOW and OW, the number of subjects with flat feet was in both groups negligible.
\end{abstract}

Keywords: multi-frequency bioimpedance, percent body fat, longitudinal foot arch, foot parameters, Chippaux-Smirak index

\section{Introduction}

Obesity and being overweight are major risk factors for many chronic diseases. Overweight and obese people are the majority today in the OECD area. Before 1980, however, fewer than one in ten people were obese in OECD countries. In the following decades, rates have doubled or even tripled and are continuing to rise (Wilson, Devaux, Cecchini, \& Sassi, 2014). The number of overweight and obese people rose to 2.1 billion in 2013, according to a major new analysis from the Global Burden of Disease Study 2013, published in The Lancet (Ng et al., 2014). Being overweight and obese are associated with a musculoskeletal state and are responsible for significant disabilities and impaired quality of life (Anandacoomarasamy, Caterson, Sambrook, Fransen, \& March, 2008; Butterworth, Landorf, Smith, \& Menz, 2012; Hills, Hennig, Byrne, \& Steele, 2002).

\footnotetext{
* Address for correspondence: Kristína Tománková, Department of Natural Sciences in Kinanthropology, Faculty of Physical Culture, Palacký University Olomouc, třída Míru 117, 77111 Olomouc, Czech Republic. E-mail: kristina.tomankova@upol.cz
}

As a result of postmenopausal changes; body fat mass $(\mathrm{kg})$ rises in women by $0.4 \mathrm{~kg} / \mathrm{year}$ to the age of 50 , then to 75 years it rises more rapidly and then slightly decreases thereafter (Gába \& Přidalová, 2014; Guo, Zeller, Chumlea, \& Siervogel, 1999; Kyle, Genton, Hans, Karsegard, Slosman, \& Pichard, 2001). Women with percent body fat (PBF) over 35\% are considered obese (Dickey et al., 1998; Heyward \& Wagner, 2004). Obesity in older people is often connected with excessive body mass, lower physical fitness rates, and an increased number of falls (Domaradzki, Ignasiak, \& Stodółka, 2014). In addition, older people with foot deformities have been identified as having an increased risk of falling (Mickle, Munro, Lord, Menz, \& Steele, 2011). Furthermore, subjects who fall can develop a fear of falling, which may further limit their physical and social activities (Jinseop, Kyoung, \& Gubler, 2013). This creates a vicious cycle associated with obesity where obesity is ultimately strengthened.

Obesity is strongly associated with planus (lowarched) foot posture, pronated dynamic foot function and increased plantar pressures when walking (Butterworth, Landorf, Gilleard, Urquhart, \& Menz, 2014). Among the main problems connected with obesity are toe deformities (hallux valgus, hallux varus, digitus 
quintus varus), widening of the forefoot and heel area, transversal arch collapse in the metatarsal area, metatarsalgia, flat footedness (the collapse of the mid-foot area of the longitudinal arch) and heel misalignment (Butterworth et al., 2014; Butterworth et al., 2012; Hills et al., 2002; Wearing, Hennig, Byrne, Steele, \& Hills, 2006).

There are many studies which have confirmed that being overweight and obese documents a high body mass index (not body composition) having undesirable negative effects on the feet, probably due to the greater mechanical loading of the lower limbs (Birtane \& Tuna, 2004; Butterworth et al., 2014; Butterworth et al., 2012; Domjanic, Fieder, Seidler, \& Mitteroecker, 2013; Hills, Hennig, McDonald, \& Bar-Or, 2001; Morag \& Cavanagh, 1999; Wearing, Hills, Byrne, Hennig, \& McDonald, 2004); however, studies also exist with contradictory, neutral and positive findings (Nguyen et al., 2010). People with higher Body Mass Index (BMI) may not have been obese from aspect of body composition (Evans, Rowe, Racette, Ross, \& McAuley, 2006; Gába, Přidalová, \& Zajac-Gawlak, 2014; Romero-Corral et al., 2008), but the methodological question of BMI objectivity is not aim of this study.

Scientific opinions vary regarding how body composition (body fat and other components) affects the feet. It is believed that body fat mass, rather than changes in foot morphology and structure, may be the cause of an increased mid-foot contact area and, ultimately, fallen arches (Alcantara, Forner, Ferrus, Garcia, \& Ramiro, 2012; Butterworth et al., 2014; Wearing et al., 2004). The strength of association between body composition components and foot morphology and structure, likewise foot function, is still unclear (Butterworth et al., 2014). Thus, it is very important to investigate the foot characteristics in association with obesity expressed as the selected body components. Therefore the aim of this submitted study analyses of the percent of body fat in relation to foot morphology parameters and longitudinal foot arch condition.

\section{Methods}

\section{Subjects}

The study sample comprised 139 women aged 48-69 years (age periods Maturus II. and Presenilis) divided into two groups: non-obese women with $\mathrm{PBF}<35 \%$ (NOW) with a mean age of $55.8 \pm 4.4$ years $(n=66)$ and obese women with $\mathrm{PBF}>35 \%$ (OW) with a mean age of $57.4 \pm 4.9$ years $(n=73)$, measured in the Kinanthropometry Laboratory at the Faculty of Physical Culture, Palacký University Olomouc (Table 1). All of the 139 participants recruited were informed about the purpose of this study and provided informed written consent before participation in the research process. This study was approved by the Ethics Committee of the Faculty of Physical Culture, Palacký University Olomouc.

\section{Data collection and analysis}

Women underwent the basic anthropometric measurements of body weight and body height, both as measured by a digital medical scale with a stadiometer (InBody BSM370; BioSpace, Seoul, South Korea). BMI was calculated and evaluated by WHO and the WHO classification scale which was used was as follows: underweight $\left(<18.5 \mathrm{~kg} / \mathrm{m}^{2}\right)$, normal weight $\left(<24.9 \mathrm{~kg} / \mathrm{m}^{2}\right)$, overweight $\left(<29.9 \mathrm{~kg} / \mathrm{m}^{2}\right)$ and obese $1^{\text {st }}$ degree $\left(<34.9 \mathrm{~kg} / \mathrm{m}^{2}\right), 2^{\text {nd }}$ degree $\left(<39.9 \mathrm{~kg} / \mathrm{m}^{2}\right)$ and $3^{\text {rd }}$ degree $\left(\geq 39.9 \mathrm{~kg} / \mathrm{m}^{2}\right)$ (World Health Organization, 2012). The percent body fat (PBF) was estimated by the multi-frequency bioimpedance method (InBody 720; BioSpace, Seoul, South Korea). The multifrequency bioimpedance method (MF-BIA) appears to be an appropriate method for the assessment of body composition in post-menopausal woman with $\mathrm{BMI}>30 \mathrm{~kg} / \mathrm{m}^{2}$ and in these who are insufficiently

Table 1

Age and somatic parameters in non-obese and obese women

\begin{tabular}{|c|c|c|c|c|c|c|c|c|}
\hline & \multicolumn{4}{|c|}{ Non-obese women $(n=66)$} & \multicolumn{4}{|c|}{ Obese women $(n=73)$} \\
\hline & $M \pm S D$ & $M d n$ & Min. & Max. & $M \pm S D$ & $M d n$ & Min. & Max. \\
\hline Age (years) & $55.7 \pm 4.5$ & 55 & 48 & 67 & $57.4 \pm 5.0$ & 57 & 49 & 69 \\
\hline Body height (cm) & $163.5 \pm 5.6$ & 162.7 & 150.5 & 176.2 & $163.0 \pm 4.5$ & 163.1 & 153.7 & 173.9 \\
\hline Body weight (kg) & $62.5 \pm 8.6$ & 62.3 & 47.8 & 87.9 & $82.4 \pm 14.3$ & 79.6 & 59.2 & 130.9 \\
\hline BMI $\left(\mathrm{kg} / \mathrm{m}^{2}\right)$ & $23.3 \pm 2.6$ & 23.2 & 18.8 & 28.7 & $31.0 \pm 5.7$ & 29.9 & 23.5 & 49.6 \\
\hline PBF (\%) & $28.8 \pm 5.1$ & 30.1 & 15.3 & 34.8 & $41.5 \pm 4.9$ & 39.97 & 35.2 & 54.5 \\
\hline
\end{tabular}

Note. $\mathrm{PBF}=$ percent body fat 
active (Gába, Kapuš, Cuberek, \& Botek, 2014). Obesity was interpreted by PBF. Only PBF was used for further analysis. Women with a PBF of over $35 \%$ are considered obese (Heyward \& Wagner, 2004). In order to obtain morphological and structural characteristics static podograms of the both feet were made which were taken by means of a footprint device with a special rubber membrane. The lower part of the membrane was ink-colored and under the membrane was situated blank A3 paper. When the participant stepped on the membrane with both feet from a seated position (while on a chair in a position of a $90^{\circ}$ angle at the knee joint) to a standing position, it created black ink imprints on the blank paper. Podograms were used to scan it into digital form and were evaluated with the custommade software "Foot" (Elfmark \& Přidalová, 2002), where basic length, width and angle parameters were assessed. Measurements included foot parameters on both feet. Angle parameters included the hallux angle, the digitus minimus angle, the heel angle and the foot angle (Figure 1). When the first three angles were positive values, a valgus position was indicated; when values were negative it indicated a varus position. Three categories were used for foot angles: I. $<15^{\circ}$, II. $15-18^{\circ}$ and III. $>18^{\circ}$ (Přidalová \& Riegerová, 2005). Length parameters included heel length and foot length. Width parameters included direct forefoot width and direct heel width. The next parameter which evaluated the longitudinal foot arch was the Chippaux-Smirak index (CSI). The CSI (\%) was calculated as the ratio of the widest part (direct forefoot width) and the narrowest

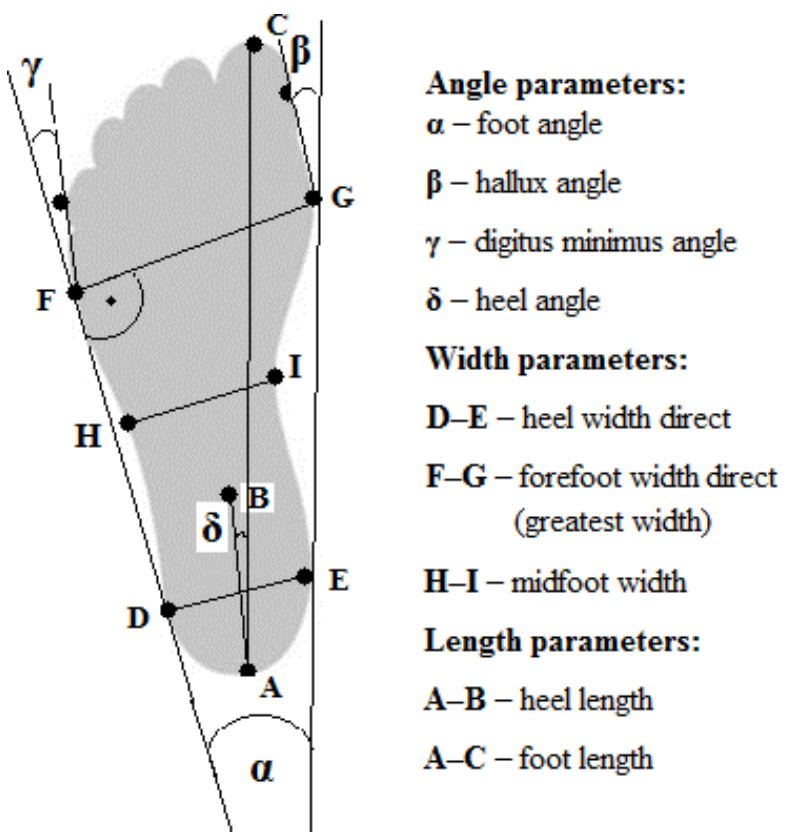

Figure 1. Measured foot parameters part of the midfoot and then multiplying it by 100 . Values in the range of $0.1-45.0 \%$ indicated a normally arched foot and values higher than $45.1 \%$ indicated flat footedness (pes planus) (Figure 2). If the mid-foot was missing in the footprint, it indicated a high-arched foot (pes excavatus) and then we measured the blank space in the footprint between the forefoot and the heel (Klementa, 1987).

\section{Statistical analysis}

We applied descriptive statistical methods for the base analysis of the investigated parameters. After calculating the Shapiro-Wilk normality test for all parameters, which confirmed non-normality of data distribution, we used the Mann-Whitney $U$ test $(Z)$ for the evaluation of differences between the NOW and OW. Additionally, we calculated effect size coefficient $\left(r_{\mathrm{pb}}\right)$ according the formula: $r_{\mathrm{pb}}=Z / \sqrt{ } N$, only for significant results $(p<.05)$. Value range for effect size was: $.1<r_{\mathrm{pb}}<.3$ - small effect, $.3<r_{\mathrm{pb}}<.5$ - medium effect, $r_{\mathrm{pb}}>.5-$ strong effect (Cohen, 1988). Values of the effect size $r_{\mathrm{pb}}>.1$ were further discussed. Statistical analysis was performed by STATISTICA software (Version 12; StatSoft, Tulsa, OK, USA).

\section{Results}

On the left foot there was a significant difference between the NOW and OW $\left(2.9^{\circ}, p=.01, r_{\mathrm{pb}}=.25\right)$ (Table 2). Hallux valgus angle was smaller in the OW.

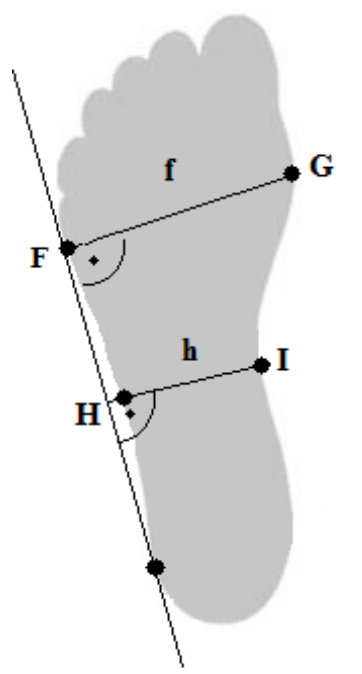

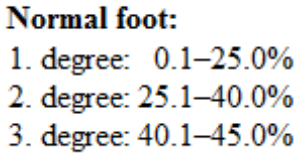

Flat foot:

1. degree: $45.1-50.0 \%$

2. degree: $50.1-60.0 \%$

3. degree: $60.1-100.0 \%$

High foot:

(when the middle part of foot missing, we measure the length of blank space)

1. degree: $0.1-1.5 \mathrm{~cm}$

2. degree: $1.6-3.0 \mathrm{~cm}$

3. degree: $>3.1 \mathrm{~cm}$

$$
\begin{aligned}
& \text { CSI }(\%)=(\text { h / f }) \times 100 \\
& \text { f }(F-G)-\text { greatest forefoot width } \\
& \text { h }(\mathbf{H}-\mathbf{I})-\text { smallest midfoot width }
\end{aligned}
$$

Figure 2. The Chippaux-Smirak index (CSI) method (modified from Přidalová \& Riegerová, 2005) 
Otherwise, hallux varus dominated (average values and frequency) (Table 2) in the OW on the left foot. Regarding heel width, the great impact of obesity was demonstrated; the significant difference between the NOW and the OW was $34 \mathrm{~mm}\left(p=.01, r_{\mathrm{pb}}=.20\right)$. Similar was the situation of the forefoot width; the difference between the NOW and the OW was $22 \mathrm{~mm}(p=.02$, $\left.r_{\mathrm{pb}}=.20\right)$. The difference between the NOW and the
OW was $7.8 \%\left(p<.01, r_{\mathrm{pb}}=.26\right)$ when considering the CSI of the left foot. With increased PBF the average value of the CSI increases, but neither group scored an unreasonable level of pes planus, probably therefore the real number of women with pes planus on the left foot was negligible (only $4.5 \%$ of the total sample; $n=3$ ).

The significant impact of obesity was observed on the right foot only in two parameters (Table 3 ). The

Table 2

Comparison of the left foot parameters between non-obese and obese women

\begin{tabular}{|c|c|c|c|c|c|c|c|c|}
\hline & \multicolumn{2}{|c|}{ Non-obese women $(n=66)$} & \multicolumn{2}{|c|}{ Obese women $(n=73)$} & \multirow[b]{2}{*}{$\mathrm{D}$} & \multirow[b]{2}{*}{$Z$} & \multirow[b]{2}{*}{$p$} & \multirow[b]{2}{*}{$r_{\mathrm{pb}}$} \\
\hline & $M \pm S D$ & $M d n$ & $M \pm S D$ & $M d n$ & & & & \\
\hline Foot angle $\left({ }^{\circ}\right)$ & $15.5 \pm 6.3$ & 16.5 & $13.4 \pm 9.4$ & 15.5 & 2.1 & 1.32 & .19 & $.11 *$ \\
\hline Hallux angle $\left({ }^{\circ}\right)$ & $9.8 \pm 8.0$ & 10.0 & $4.5 \pm 9.8$ & 5.7 & 5.3 & 3.42 & $<.01$ & $.29 *$ \\
\hline \multirow[t]{2}{*}{ Hallux varus $\left({ }^{\circ}\right)$} & $n=8$ & & $n=19$ & & & & & \\
\hline & $-4.3 \pm 4.9$ & -2.2 & $-7.9 \pm 4.2$ & -4.1 & 3.5 & -0.82 & .41 & $.16^{*}$ \\
\hline \multirow[t]{2}{*}{ Hallux valgus $\left({ }^{\circ}\right)$} & $n=58$ & & $n=54$ & & & & & \\
\hline & $11.7 \pm 6.3$ & 11.1 & $8.8 \pm 8.9$ & 8.9 & 2.9 & -2.63 & .01 & $.25^{*}$ \\
\hline Digitus minimus angle $\left({ }^{\circ}\right)$ & $14.4 \pm 9.7$ & 16.1 & $14.9 \pm 10.3$ & 16.7 & -0.5 & -0.68 & .49 & .06 \\
\hline Heel angle $\left({ }^{\circ}\right)$ & $8.0 \pm 6.3$ & 8.8 & $7.9 \pm 7.9$ & 8.4 & 0.1 & -0.38 & .70 & .03 \\
\hline Heel width (mm) & $49.2 \pm 7.9$ & 48.9 & $52.6 \pm 4.7$ & 51.4 & -3.4 & -3.18 & .01 & $.20 *$ \\
\hline Forefoot width (mm) & $88.4 \pm 7.8$ & 87.6 & $90.6 \pm 54.0$ & 89.2 & -2.2 & -2.38 & .02 & $.20 *$ \\
\hline Heel length (mm) & $65.8 \pm 0.7$ & 65.6 & $66.8 \pm 5.5$ & 66.4 & -0.9 & -1.00 & .02 & .08 \\
\hline Foot length (mm) & $232.6 \pm 9.8$ & 232.5 & $233.8 \pm 10.7$ & 233.0 & -1.1 & -0.62 & .54 & .05 \\
\hline CSI (\%) & $24.5 \pm 14.9$ & 28.2 & $32.3 \pm 11.1$ & 34.1 & -7.8 & -3.11 & $<.01$ & $.26^{*}$ \\
\hline
\end{tabular}

Note. $\mathrm{PBF}=$ percent body fat, $\mathrm{CSI}=$ Chippaux-Smirak index, $\mathrm{D}=$ difference, $Z=$ Mann-Whitney test,$p=$ statistical significance, $r_{\mathrm{pb}}=$ effect size, *small effect.

Table 3

Comparison of right foot parameters between non-obese and obese women

\begin{tabular}{|c|c|c|c|c|c|c|c|c|}
\hline & \multicolumn{2}{|c|}{ Non-obese women $(n=66)$} & \multicolumn{2}{|c|}{ Obese women $(n=73)$} & \multirow[b]{2}{*}{$\mathrm{D}$} & \multirow[b]{2}{*}{$Z$} & \multirow[b]{2}{*}{$p$} & \multirow[b]{2}{*}{$r_{\mathrm{pb}}$} \\
\hline & $M \pm S D$ & $M d n$ & $M \pm S D$ & $M d n$ & & & & \\
\hline Foot angle $\left({ }^{\circ}\right)$ & $14.3 \pm 8.5$ & 16.2 & $14.7 \pm 7.7$ & 16.5 & -0.4 & -0.51 & .61 & .04 \\
\hline Hallux angle $\left({ }^{\circ}\right)$ & $5.1 \pm 9.6$ & 7.0 & $4.9 \pm 9.2$ & 5.5 & 0.2 & 0.51 & .61 & .04 \\
\hline \multirow[t]{2}{*}{ Hallux varus $\left({ }^{\circ}\right)$} & $n=14$ & & $n=21$ & & & & & \\
\hline & $-8.3 \pm 8.9$ & -6.3 & $-5.9 \pm 5.6$ & -5.5 & -2.4 & 0.00 & $>.99$ & $<.01$ \\
\hline \multirow[t]{2}{*}{ Hallux valgus $\left({ }^{\circ}\right)$} & $n=52$ & & $n=52$ & & & & & \\
\hline & $8.7 \pm 5.9$ & 7.7 & $9.3 \pm 8.7$ & 8.6 & -0.7 & 0.66 & .51 & .06 \\
\hline Digitus minimus angle $\left({ }^{\circ}\right)$ & $13.3 \pm 10.9$ & 15.5 & $15.3 \pm 9.1$ & 16.7 & -2.0 & -1.12 & .26 & .09 \\
\hline Heel angle $\left({ }^{\circ}\right)$ & $8.8 \pm 6.2$ & 9.5 & $9.5 \pm 6.2$ & 10.0 & -0.7 & -0.79 & .43 & .06 \\
\hline Heel width (mm) & $49.9 \pm 4.3$ & 48.9 & $52.3 \pm 4.4$ & 50.7 & -2.3 & -2.62 & $<.01$ & $.22 *$ \\
\hline Forefoot width (mm) & $87.9 \pm 5.7$ & 87.6 & $89.7 \pm 5.4$ & 89.0 & -1.8 & -1.71 & .09 & $.14 *$ \\
\hline Heel length (mm) & $65.1 \pm 4.8$ & 65.6 & $66.0 \pm 5.4$ & 65.2 & -0.9 & -0.79 & .43 & .06 \\
\hline Foot length (mm) & $231.6 \pm 10.3$ & 232.5 & $232.9 \pm 9.9$ & 232.0 & -1.3 & 0.65 & .52 & .05 \\
\hline CSI $(\%)$ & $24.0 \pm 14.9$ & 28.2 & $32.0 \pm 11.3$ & 35.1 & -8.0 & -3.28 & $<.01$ & $.27 *$ \\
\hline
\end{tabular}

Note. $\mathrm{PBF}=$ percent body fat, $\mathrm{CSI}=$ Chippaux-Smirak index, $\mathrm{D}=$ difference, $Z=$ Mann-Whitney test, $p=$ statistical significance, $r_{\mathrm{pb}}=$ effect size, *small effect. 
difference between the NOW and the OW in the heel width was $23.7 \mathrm{~mm}\left(p<.01, r_{\mathrm{pb}}=.22\right)$. The CSI index showed a very similar situation as on the left foot. The difference between the NOW and the OW was $8.0 \%$ $\left(p<.01, r_{\mathrm{pb}}=.27\right)$. The average values of the CSI did not show unreasonable levels of flat footedness, likely meaning that the real number of women with pes planus on their right feet was small (only $6.8 \%$ of the total sample; $n=5$ ), however obesity did burden the longitudinal foot arch (Table 4). There was not a significant impact of obesity in most other cases.

\section{Discussion}

Although many studies observed the impact of body composition on foot morphology, we think that it has not been explored completely. The first dispute is the evaluation of obesity, as was shown, for example, in the study by Gába, Přidalová, et al. (2014), where 14\% of women with normal BMIs and $70 \%$ of overweight women showed obesity expressed as PBF $>35 \%$. This means that the objectivity of BMI can be questionable. The fundamental problem is that most of the study investigated foot disorders only in association with BMI. Therefore, it is very important to extend the database of body composition results.
In this study, the impact of obesity (established by the MF-BIA), particularly on longitudinal foot arch, was found. Longitudinal foot arch was quite affected by obesity. The difference of the CSI between the NOW and the OW was $7.8 \%$ with small effect. With increased PBF the average value of the CSI increases, but neither group scored unreasonable levels of pes planus, likely meaning that the real number of women with foot pes planus was negligible ( $\sin .4 .5 \%$ of the total sample; $n=3$, dex. $6.8 \%$ of the total sample; $n=5$ ) (Table 4). Negligible results proved the study done by Xiong, Goonetilleke, Witana, Weerasinghe, and $\mathrm{Au}$ (2010) when results showed no significant differences in weight, BMI and body fat content between three groups of young adults by arch type (high, normal and low arch). These parameters showed tendency to increase with foot arch collapsing, similarly. Another study showed that subjects with a lower arch appeared to have a greater BMI, meaning body mass has a significant, but medium effect $\left(r_{\mathrm{pb}}=.36, p<.05\right)$ (Schie \& Boulton, 2000). To put it another way, the significant results of a study done by Morag and Cavanagh (1999) showed that excess body weight is a potential predictor for greater plantar pressure peak under the mid-foot, which are in accordance with our results. Similarly, significant effect of the BFM on the arch index and the mid-foot contact area (Wearing et al., 2004) was proven. In this area Birtane and Tuna (2004) showed

Table 4

Frequency of foot arch types in non-obese and obese women

\begin{tabular}{|c|c|c|c|c|c|c|c|c|c|c|}
\hline \multirow[b]{3}{*}{ Foot arch type } & \multicolumn{4}{|c|}{ Non-obese women } & \multicolumn{4}{|c|}{ Obese women } & \multicolumn{2}{|c|}{ Total } \\
\hline & \multicolumn{2}{|c|}{$\sin }$. & \multicolumn{2}{|c|}{ dex. } & \multicolumn{2}{|c|}{$\sin }$. & \multicolumn{2}{|c|}{ dex. } & \multirow{2}{*}{$\frac{\sin .}{n}$} & \multirow{2}{*}{$\frac{\text { dex. }}{n}$} \\
\hline & $n$ & $\%$ & $n$ & $\%$ & $n$ & $\%$ & $n$ & $\%$ & & \\
\hline \multicolumn{11}{|l|}{ Normal foot } \\
\hline 1. & 15 & 22.7 & 23 & 34.9 & 11 & 15.1 & 17 & 23.3 & 26 & 40 \\
\hline 2. & 32 & 48.5 & 30 & 45.5 & 46 & 63.0 & 41 & 56.2 & 78 & 71 \\
\hline 3. & 6 & 9.1 & 2 & 3.0 & 9 & 12.3 & 9 & 12.3 & 15 & 11 \\
\hline Total & 53 & 80.3 & 55 & 83.3 & 66 & 90.4 & 67 & 91.8 & 119 & 122 \\
\hline \multicolumn{11}{|l|}{ Flat foot } \\
\hline 1. & 2 & 3.0 & 1 & 1.5 & 4 & 5.5 & 2 & 2.7 & 6 & 3 \\
\hline 2. & 1 & 1.5 & 1 & 1.5 & 1 & 1.4 & 3 & 4.1 & 2 & 4 \\
\hline 3. & 0 & 0.0 & 1 & 1.5 & 0 & 0.0 & 0 & 0.0 & 0 & 1 \\
\hline Total & 3 & 4.6 & 3 & 4.6 & 5 & 6.9 & 5 & 6.9 & 8 & 8 \\
\hline \multicolumn{11}{|l|}{ High floot } \\
\hline 1. & 0 & 0.0 & 0 & 0.0 & 0 & 0.0 & 1 & 1.4 & 0 & 1 \\
\hline 2. & 1 & 1.5 & 2 & 3.0 & 0 & 0.0 & 0 & 0.0 & 1 & 2 \\
\hline 3. & 9 & 13.6 & 6 & 9.1 & 2 & 2.7 & 0 & 0.0 & 11 & 6 \\
\hline Total & 10 & 15.2 & 8 & 12.1 & 2 & 2.7 & 1 & 1.4 & 12 & 9 \\
\hline Total & 66 & 100.0 & 66 & 100.0 & 73 & 100.0 & 73 & 100.0 & 139 & 139 \\
\hline
\end{tabular}

Note. $\mathrm{PBF}=$ percent body fat 
interesting results. These authors compared plantar pressure between obese a non-obese subjects in each foot region. Every foot region was dominated from just the middle foot peak pressure in obese subjects. This means that foot arch is the most-attacked part of the foot. The second important finding in this study concerns differences in width parameters similarly as in our study.

We found similar results regarding forefoot width on both the left and right feet. The difference between the NOW and the OW was $22 \mathrm{~mm}\left(r_{\mathrm{pb}}=.20\right)$ for left and $17.9 \mathrm{~mm}$ for right feet. The obesity impact was small to low. Age, gender and obesity have been shown to introduce significant differences in heel properties (Alcantara et al., 2012). Forefoot and heel width have shown the impact of obesity. The difference was $23.7 \mathrm{~mm}$ and this parameter was the greatest affected of all parameters from obesity when considering the right foot $\left(r_{\mathrm{pb}}=.22\right)$. Our findings confirmed the study done by Hills et al. (2001) where obese subjects showed increased forefoot width. This study also proved that higher plantar pressure dominated in the heel and midfoot area. Yet, some studies showed no effect of obesity on forefoot width (Guven, Ozden, Akalin, \& Colak, 2009). The heel width parameter is closely related to foot angle. Only on the left foot showed differences between the NOW and the OW in the foot angle $\left(2.1^{\circ}\right)$. A decline in value was likely caused by obesity through the expanse of the heel width. The probable reason why left foot is more attacked then right foot could be overloading of support limb, but it can be also impact other important factors which not examined in this study.

Finally, we found differences also in the hallux valgus and varus angle parameters. The right foot showed no significant differences between the NOW and the OW, but we observed a much higher hallux valgus angle in non-obese subjects (difference $2.9^{\circ}$, small effect) on the left foot. Otherwise, the OW showed lower average values of the hallux varus angle (difference $3.5^{\circ}$ ). The surprising fact that the non-obese subjects have higher hallux angles was confirmed by findings in the study by Nguyen et al. (2010). This shows that obesity appears to be "protective" against the hallux valgus. Similarly, an analysis of another study by Frey and Zamora (2007) found the hallux valgus more likely in groups with normal BMIs than among the obese. It seems that the obesity impacts the hallux varosity much more than the valgosity.

\section{Conclusions}

In conclusion, selected morphology parameters seem to be significantly influenced by obesity, which was expressed as percent body fat. Mainly, it was the longitudinal foot arch, whose average value of the CSI were pointedly the most-affected of all the investigated parameters resulting from load stemming due to obesity; such was true on both feet, but was not observed to have an effect on final foot arch collapse. Surprisingly, a significantly higher average value of the hallux valgus angle on the left foot in non-obese subjects and not in the obese was recorded. Otherwise, significantly higher values of the hallux varus angle on the left foot only were in the OW. Width parameters, specifically forefoot width and heel width, also showed significant differences between non-obese and obese subjects on both feet. The OW had higher forefoot width and heel width. These findings are in agreement with other studies. On the basis of submitted results, obesity represents some mechanical load on the lower limb, especially the foot. Obesity significantly changes foot morphology, causing hallux varosity, widening of the forefoot, as well as heel widening.

\section{Acknowledgment}

The authors would like to thank the volunteers who participated in this research study. The study was supported by European Structural Funds grant entitled Support for the creation of excellent research teams and intersectoral mobility at the Palacký University in Olomouc II. (No. CZ.1.07/2.3.00/30.0041) and by the Czech Science Foundation grant entitled The analysis of health-related benefits of walking: Assessment of walking intervention in sedentary adults (No. 13-32105S).

\section{References}

Alcantara, E., Forner, A., Ferrus, E., Garcia, A., \& Ramiro, J. (2012). Influence of age, gender and obesity on the mechanical properties of the heel pad under walking impact conditions. Journal of Applied Biomechanics, 18, 345-346.

Anandacoomarasamy, A., Caterson, I., Sambrook, P., Fransen, M., \& March, L. (2008). The impact of obesity on the musculoskeletal system. International Journal of Obesity, 32, 211-222. doi:10.1038/sj.ijo.0803715

Birtane, M., \& Tuna, H. (2004). The evaluation of plantar pressure distribution in obese and non-obese adults. Clinical Biomechanics, 19, 1055-1059. doi:10.1016/j. clinbiomech.2004.07.008

Butterworth, P. A., Landorf, K. B., Gilleard, W., Urquhart, D. M., \& Menz, H. B. (2014). The association between body composition and foot structure and function: A systematic review. Obesity Reviews, 15, 348-357. doi:10.1111/ obr. 12130

Butterworth, P. A., Landorf, K. B., Smith, S. E., \& Menz, H. B. (2012). The association between body 
mass index and musculoskeletal foot disorders: A systematic review. Obesity Reviews, 13, 630-642. doi:10.1111/j.1467-789X.2012.00996.x

Cohen, J. (1988). Statistical power analysis for the behavioral sciences. Hillsdale, NJ: Lawrence Erlbaum Associates.

Dickey, R. A., Bartuska, D., Bray, G. W., Callaway, C. W., Davidson, E. T., Feld, S., ... Kennedy, F. P. (1998). AACE/ ACE position statement on the prevention, diagnosis, and treatment of obesity (1998 revision). Endocrine Practice, 4, 297-350.

Domaradzki, J., Ignasiak, Z., \& Stodółka, W. (2014). The predictors of falls in adult and senior women from cities of Lower Silesia, Poland. Human Movement, 15, 86-92.

Domjanic, J., Fieder, M., Seidler, H., \& Mitteroecker, P. (2013). Geometric morphometric footprint analysis of young women. Journal of Foot and Ankle Research, 6, Article ID 27.

Elfmark, M., \& Přidalová, M. (2002). Noha [Foot] [Computer Software]. Olomouc: Palacký University.

Evans, E. M., Rowe, D. A., Racette, S. B., Ross, K. M., \& McAuley, E. (2006). Is the current BMI obesity classification appropriate for black and white postmenopausal women? International Journal of Obesity, 30, 837-843.

Frey, C., \& Zamora, J. (2007). The effects of obesity on orthopaedic foot and ankle pathology. Foot and Ankle International, 28, 996-999. doi:10.3113/fai.2007.0996

Gába, A., Kapuš, O., Cuberek, R., \& Botek, M. (2014). Comparison of multi- and single-frequency bioelectrical impedance analysis with dual-energy X-ray absorptiometry for assessment of body composition in post-menopausal women: Effects of body mass index and accelerometerdetermined physical activity. Journal of Human Nutrition and Dietetics, Advance Online Publication. doi:10.1111/ jhn. 12257

Gába, A., \& Přidalová, M. (2014). Age-related changes in body composition in a sample of Czech women aged 18-89 years: A cross-sectional study. European Journal of Nutrition, 53, 167-176. doi:10.1007/s00394-013-0514-x

Gába, A., Přidalová, M., \& Zajac-Gawlak, I. (2014). Posouzení objektivity hodnocení výskytu obezity na základě body mass indexu vzhledem $\mathrm{k}$ procentuálnímu zastoupení tělesného tuku u žen ve věku 55-84 let [Evaluation of accuracy of body mass index in diagnosing of obesity in relation to body fat percentage in female aged 55-84 years]. Časopis lékařù českých, 153, 22-27.

Guo, S. S., Zeller, C., Chumlea, W. C., \& Siervogel, R. M. (1999). Aging, body composition, and lifestyle: The Fels Longitudinal Study. The American Journal of Clinical Nutrition, 70, 405-411.

Guven, G., Ozden, H., Akalin, A., \& Colak, E. (2009). Comparative evaluation of the foot measurements of women who presented to the obesity outpatient clinic in Eskisehir Osmangazi University. Turkiye Klinikleri Journal of Medical Sciences, 29, 1253-1259.

Heyward, V., \& Wagner, D. (2004). Applied body composition assessment (2nd ed.). Champaign, IL: Human Kinetics.

Hills, A. P., Hennig, E. M., Byrne, N. M., \& Steele, J. R. (2002). The biomechanics of adiposity - structural and functional limitations of obesity and implications for movement. Obesity Reviews, 3, 35-43. doi:10.1046/j.1467-789X.2002.00054.x

Hills, A. P., Hennig, E. M., McDonald, M., \& Bar-Or, O. (2001). Plantar pressure differences between obese and non-obese adults: A biomechanical analysis. International
Journal of Obesity and Related Metabolic Disorders, 25, 1674-1679. doi:10.1038/sj.ijo.0801785

Jinseop, K., Kyoung, K., \& Gubler, C. (2013). Comparisons of plantar pressure distributions between the dominant and non-dominant sides of older women during walking. Journal of Physical Therapy Science, 25, 313-315.

Klementa, J. (1987). Somatometrie nohy [Foot somatometry]. Praha: Státní pedagogické nakladatelství.

Kyle, U. G., Genton, L., Hans, D., Karsegard, L., Slosman, D. O., \& Pichard, C. (2001). Age-related differences in fat-free mass, skeletal muscle, body cell mass and fat mass between 18 and 94 years. European Journal of Clinical Nutrition, 55, 663-672. doi:10.1038/sj.ejcn.1601198

Mickle, K. J., Munro, B. J., Lord, S. R., Menz, H. B., \& Steele, J. R. (2011). Gait, balance and plantar pressures in older people with toe deformities. Gait \& Posture, 34, 347-351. doi:10.1016/j.gaitpost.2011.05.023

Morag, E., \& Cavanagh, P. R. (1999). Structural and functional predictors of regional peak pressures under the foot during walking. Journal of Biomechanics, 32, 359-370.

Ng, M., Fleming, T., Robinson, M., Thomson, B., Graetz, N., Margono, C., ... Gakidou, E. (2014). Global, regional, and national prevalence of overweight and obesity in children and adults during 1980-2013: A systematic analysis for the Global Burden of Disease Study 2013. Lancet, 384, 766781. doi:10.1016/s0140-6736(14)60460-8

Nguyen, U. S., Hillstrom, H. J., Li, W., Dufour, A. B., Kiel, D. P., Procter-Gray, E., ... Hannan, M. T. (2010). Factors associated with hallux valgus in a population-based study of older women and men: The MOBILIZE Boston Study. Osteoarthritis Cartilage, 18, 41-46. doi:10.1016/j. joca.2009.07.008

Přidalová, M., \& Riegerová, J. (2005). Child’s foot morphology. Acta Universitatis Palackianae Olomucensis. Gymnica, 35(2), 78-86.

Romero-Corral, A., Somers, V. K., Sierra-Johnson, J., Thomas, R. J., Collazo-Clavell, M. L., Korinek, J., ... Lopez-Jimenez, F. (2008). Accuracy of body mass index in diagnosing obesity in the adult general population. International Journal of Obesity, 32, 959-966. doi:10.1038/ijo.2008.11

Schie, C., \& Boulton, A. (2000). The effect of arch height and body mass on plantar pressure. Wounds, 12, 88-95.

Wearing, S. C., Hennig, E. M., Byrne, N. M., Steele, J. R., \& Hills, A. P. (2006). The biomechanics of restricted movement in adult obesity. Obesity Reviews, 7, 13-24. doi:10.1111/j.1467-789X.2006.00215.X

Wearing, S. C., Hills, A. P., Byrne, N. M., Hennig, E. M., \& McDonald, M. (2004). The arch index: A measure of flat or fat feet? Journal of Foot and Ankle Research, 25, 575-581.

Wilson, S., Devaux, M., Cecchini, M., \& Sassi, F. (2014). OECD obesity update, June 2014. Retrieved from http:// www.oecd.org/els/health-systems/Obesity-Update-2014.pdf

World Health Organization. (2012). BMI classification. Retrieved from http://apps.who.int/bmi/index. jsp?introPage=intro_3.html

Xiong, S., Goonetilleke, R. S., Witana, C. P., Weerasinghe, T. W., \& Au, E. Y. (2010). Foot arch characterization: A review, a new metric, and a comparison. Journal of the American Podiatric Medical Association, 100, 14-24. doi: $10.7547 / 1000014$ 